\title{
Global Patterns of Seasonal Variation in Human Fertility ${ }^{a}$
}

\author{
DAVID A. LAM ${ }^{b, d}$ AND JEFFREY A. MIRON ${ }^{c}$ \\ ${ }^{b}$ Department of Economics and Population Studies Center \\ University of Michigan \\ Ann Arbor, Michigan 48104 \\ ${ }^{c}$ Department of Economics \\ Boston University \\ 270 Bay State Road \\ Boston, Massachusetts 02215 \\ and \\ National Bureau of Economic Research \\ 1050 Massachusetts Avenue \\ Cambridge, Massachusetts 02138
}

\section{INTRODUCTION}

Pronounced and persistent seasonal patterns in births are observed in virtually all human populations. ${ }^{1-6}$ These seasonal patterns raise many intriguing questions about the behavioral and biological determinants of reproduction. This paper looks at seasonal patterns in births in populations around the world with a focus on two major issues. First, we examine the extent of systematic similarities and differences in seasonal patterns across populations. We pay particular attention to the well-defined but quite different patterns in the southern United States and northern Europe. We also examine the extent to which seasonal birth patterns in the southern hemisphere are a mirror image of patterns in the northern hemisphere. The second major issue we address is the extent to which temperature explains seasonal birth patterns and the differences in these patterns across countries. The effect of temperature on human fertility is an important and poorly understood issue that may be informed by analysis of seasonal patterns in births.

\section{THE MAGNITUDE OF SEASONAL FLUCTUATIONS IN BIRTHS}

It is important to recognize that seasonal movements in births are quantitatively large when compared to both medium-rum and long-run fluctuations in births. FIGURE 1 provides dramatic evidence of the relative importance of the seasonal component of births for two populations characterized by Louisiana and Sweden. Although the actual seasonal patterns are difficult to see in the graphs (they will be shown in more detail below), the graphs indicate the relative magnitude of seasonal fluctuations and their stability over time. The top panel shows the average number of

\footnotetext{
${ }^{a}$ Financial support was provided by the National Institute for Child Health and Human Development, Grant No. R01-HD22141.

${ }^{d}$ Address correspondence to: David Lam, Population Studies Center, University of Michigan, 1225 South Universiry, Ann Arbor, MI 48104-2590.
} 
births per day for each month from 1942 to 1988 in the state of Louisiana. The average number of births per day for each year is also shown.

It is instructive to compare the magnitude of seasonal fluctuations in Louisiana to the magnitude of changes in annual births associated with the rapid rise in fertility during the baby boom. From 1946 to 1959 the annual mean of births per day in Louisiana increased from 121 to 152 , a 26 percent increase. Looking across months in the year 1948, the monthly mean of births per day rose from 92 per day in May to 149
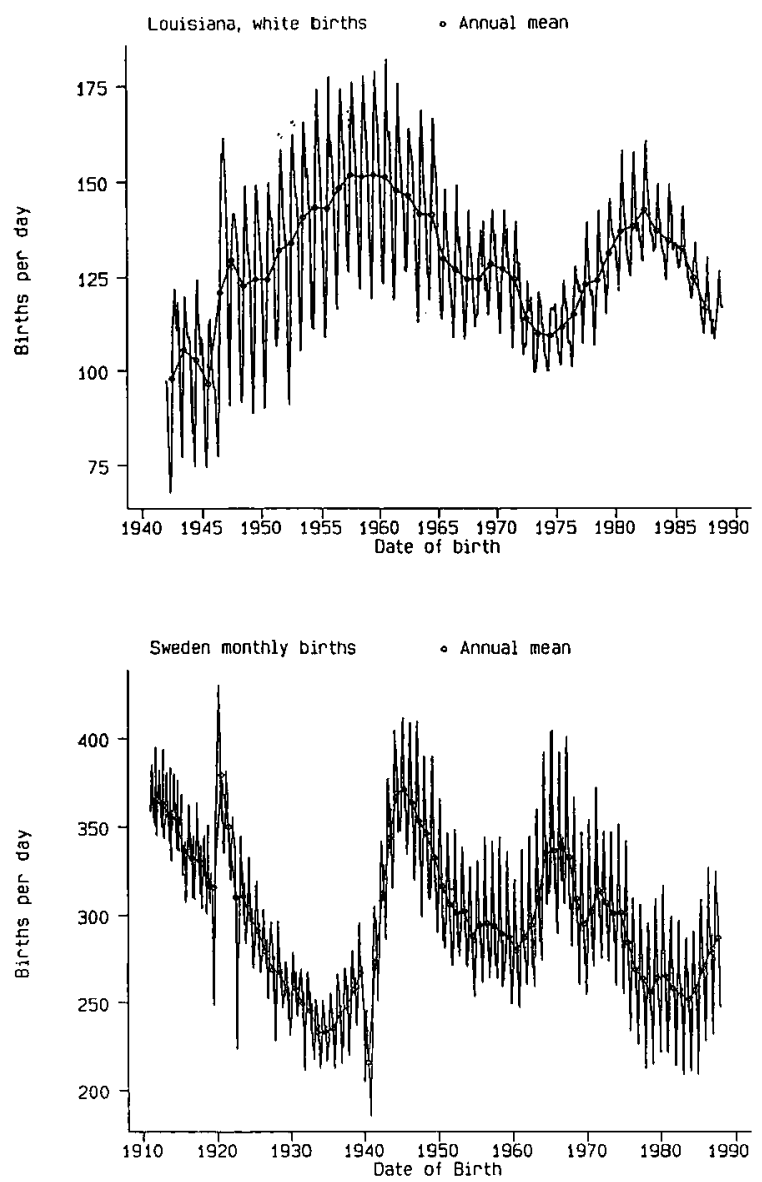

FIGURE 1. Monthly births and annual mean, Louisiana, 1942-88, and Sweden, 191 1-87.

per day in September, more than a 60 percent increase. These within-year baby booms of 45 percent to 60 percent were repeated every year between May and September in Louisiana during the 1950s. The Louisiana graph also shows a clear decline in the magnitude of seasonal fluctuations over time. Although annual means are fairly similar in the early 1950 s and early 1980s, for example, the within-year fluctuations are about twice as large in the earlier period. We document this important feature of U.S. birth seasonality more precisely below. 
The second panel of FIGURE 1 shows monthly births in Sweden from 1911 to 1987, along with the annual means. As in the graph for Louisiana we see that seasonal fluctuations in births within any given year are as large as many of the medium-run fluctuations in annual births in Sweden. The dramatic fall in fertility from around 1965 to 1980 , for example, was reflected in about a 30 percent decline in mean annual births. As seen in the graph, within-year fluctuations throughout this period were at least this large, with differences from the peak month to the trough month typically around 35 percent. Unlike the Louisiana graph, the Swedish plot of monthly births shows a clear increase in the magnitude of seasonal fluctuations, a surprising pattern that will be analyzed in more detail below.

\section{Global Patterns in Birth Seasonality}

We do not attempt to provide an exhaustive summary of seasonal patterns in births around the world. For more extensive surveys of global patterns see Lam and Miron ${ }^{5}$ and Dyson and Crook. ${ }^{4}$ Here we concentrate on demonstrating several important regional patterns that can be reliably established using long time series of vital statistics data. The seasonal patterns are estimated using regressions of detrended births on dummy variables for each month. The number of births per month is divided by the number of days in the month to adjust for the length of the month. Monthly births are detrended by taking the ratio of births in a month to the centered 12 -month average.

We begin with the pattern for the southern United States, one of the most pronounced, persistent, and best-documented seasonal birth patterns. FIGURE 2 presents the seasonal patterns in births for white and nonwhite births in the states of Louisiana, Georgia, and New York. Data for each state are divided into two time periods, 1942-68 and 1969-88. (U.S. vital statistics are classified as white and nonwhite prior to 1969, and as white and black beginning in 1969.) The figure documents both regional differences and changes over time in seasonal patterns.

The typical U.S. pattern, as noted in previous studies, ${ }^{1,2,7-10}$ is a September peak and an April-May trough. As the figure demonstrates, the April-May trough, which corresponds to July-August conceptions, is more pronounced in Louisiana and Georgia than in New York, and is more pronounced for nonwhite births than for white births. The pattern for nonwhite births in Louisiana for the early period is almost identical to the pattern for white births. The pattern for white births falls dramatically over time, however, while the pattern for nonwhite births remains almost constant. The decline in birth seasonality for whites in the U.S. South has been documented in previous research by Querec and Spratley ${ }^{11}$ and Seiver. ${ }^{9}$ Seiver argues that increased air conditioning plays an important role in the decline in birth seasonality over time. This hypothesis could be consistent with the much smaller decline for nonwhites if nonwhites had less access to air conditioning over this period.

The seasonal patterns in New York continue to show a September peak in births, although it is equal to or sometimes exceeded by July births. The April-May trough that is so pronounced in southern states appears clearly in the pattern for nonwhites in New York, but is barely evident in the pattern for white births in New York. The predominant trough in the white births occurs in December and January, which have about 10 percent fewer births than September. The patterns for both whites and nonwhites in New York are remarkably constant over time.

FIGURE 3 shows patterns for several other states in the United States, along with the patterns for two time periods in Canada. The southern states of Texas and Arizona continue to show the typical southern pattern exhibited by Louisiana and Georgia in FIGURE 2. Both states show substantial declines in the magnitude of seasonality over 
White Births, Louisiana

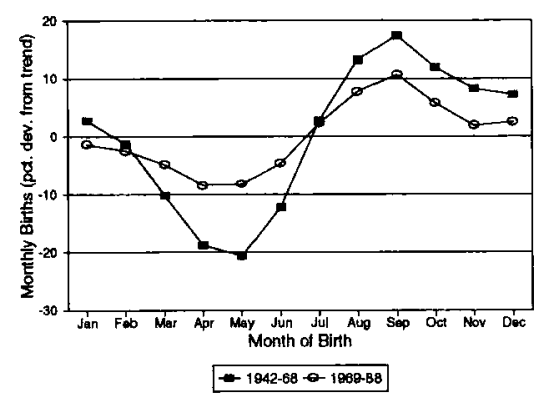

White Births, Georgia

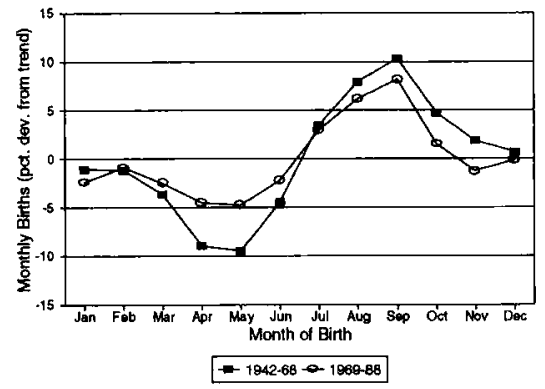

White Births, New York

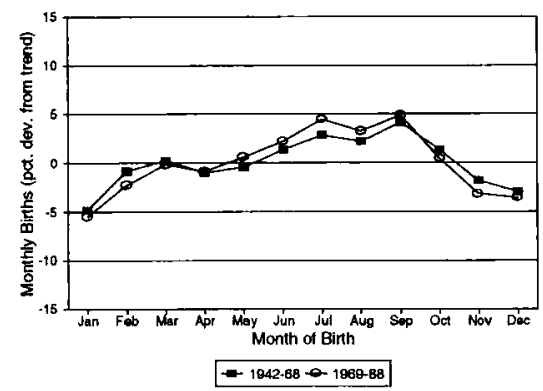

Nonwhite Births, Louisiana

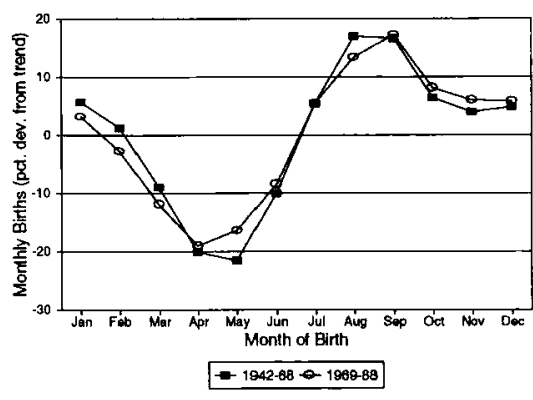

Nonwhite Births, Georgia

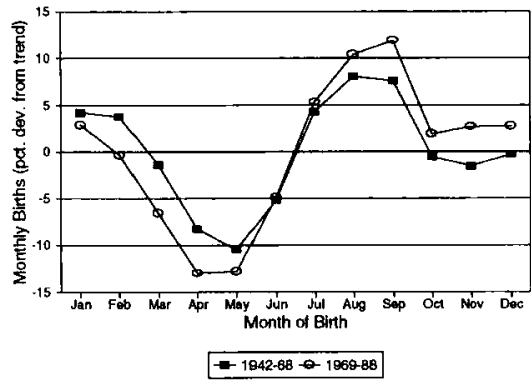

Nonwhite Births, New York

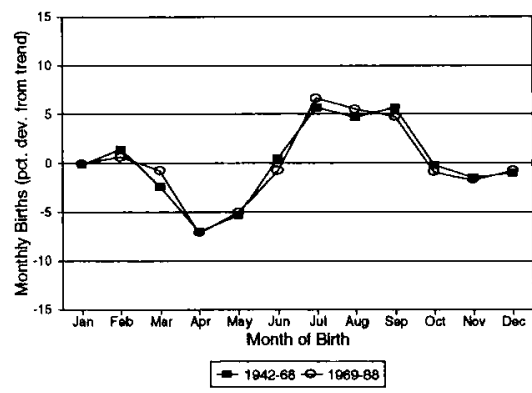

FIGURE 2. Seasonal birth patterns for white and nonwhite births, Louisiana, Georgia, and New York.

time. California shows an extreme September peak, a January trough, and almost no change in the pattern over time. Minnesota's pattern is similar to New York's and that of other north-central and north-eastern states. There is a reduction in the magnitude of the April-May trough over time.

The seasonal birth pattern in the state of Washington is dominated by a trough in November-January, a local peak in September, with relatively constant births from March through September. The pattern changes very little over time. The pattern is similar to that for Canada. Like all parts of the United States, Canada has a September peak followed by a reduction in births in October through January. The April-May trough of the southern United States appears to have given way to an April peak, 
suggesting that the apparent conception-reducing effect of summer heat does not exist in Canada. The seasonal pattern in Canada shows little change from 1948-62 to 1963-76.

FIGURE 4 shows seasonal patterns for several European countries. We see that the pattern exhibited by Canada in the previous figure is similar to that of many European populations. The "European pattern" of birth seasonality consists of a global spring peak, a local Scptember peak, and a significant trough during the late fall and early winter. In several of these countries the change from peak to trough is as high as $\mathbf{3 0}$ percent, with the seasonal dummies explaining as much as 80 percent of the non-trend variation in births. This European pattern is markedly different from the U.S. pattern,

White Births, Texas

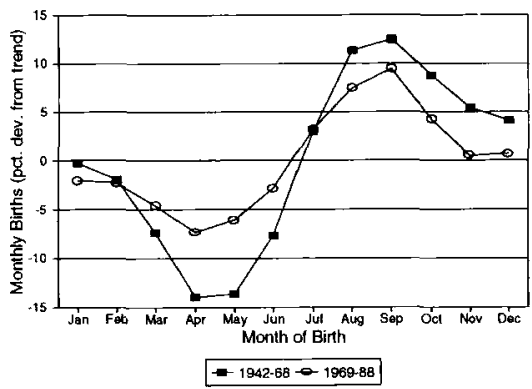

White Births, California

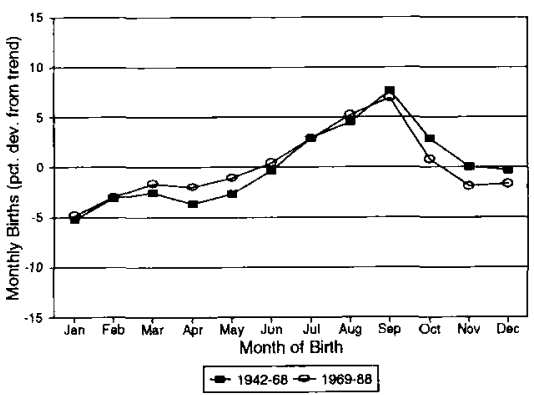

White Births, Washington

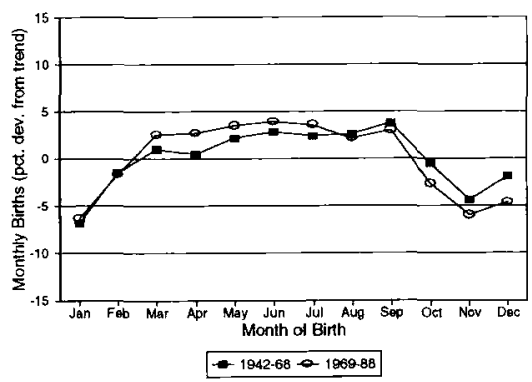

White Births, Arizona

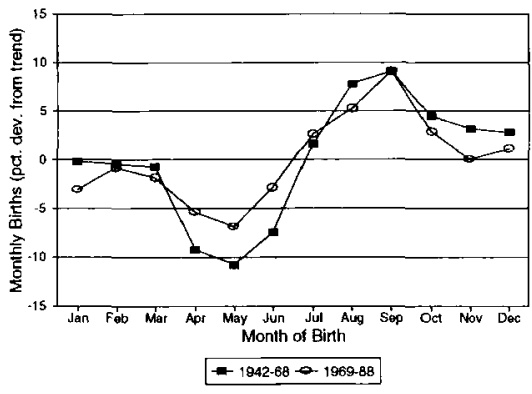

White Births, Minnesota



Canada

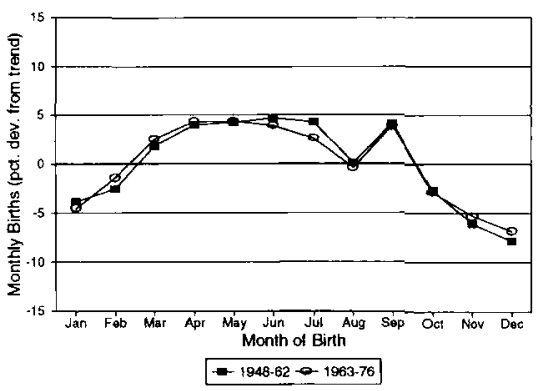

FIGURE 3. Seasonal birth patterns for Texas, Arizona, California, Minnesota, Washington, and Canada. 
particularly the spring peak in Europe as opposed to the spring trough in the United States.

There are several significant features of the seasonal patterns shown for Sweden. The magnitude of the seasonal fluctuations in births in Sweden is large, reaching a 30

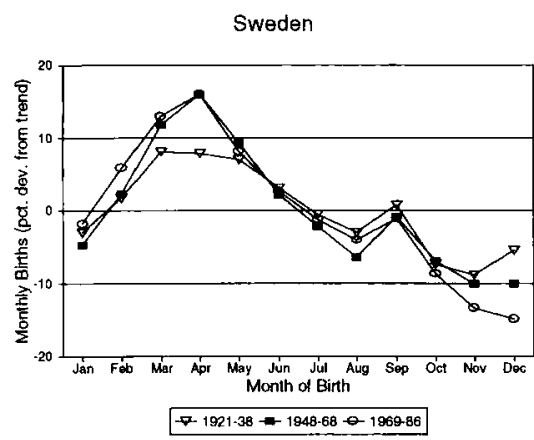

England

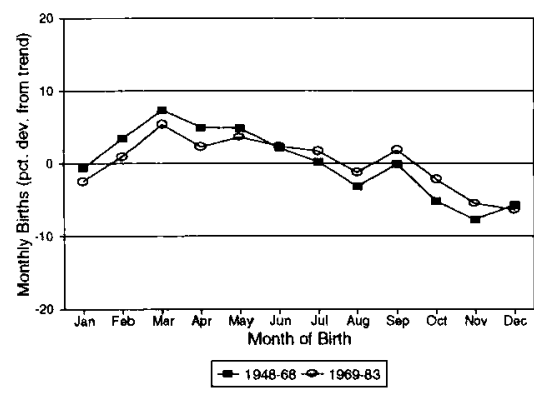

Luxembourg

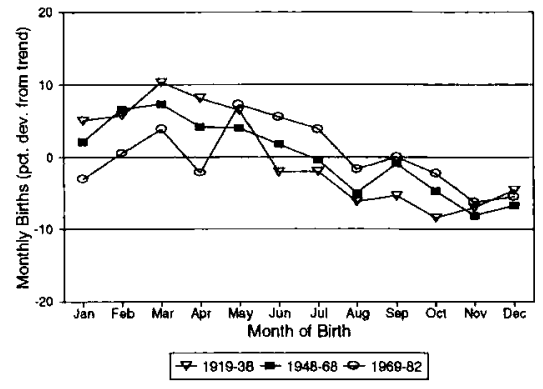

Finland

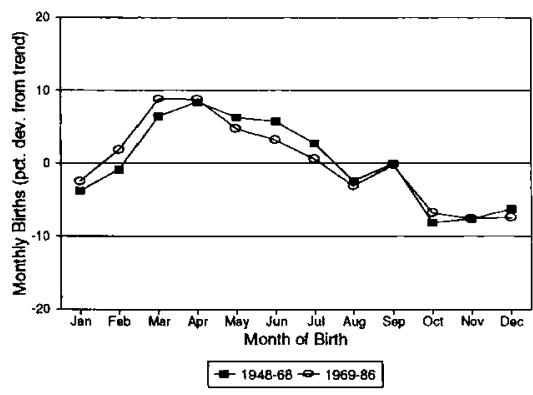

Netherlands and West Germany

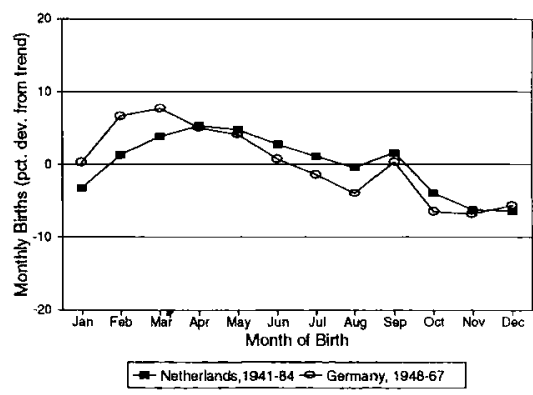

France, Italy, and Spain

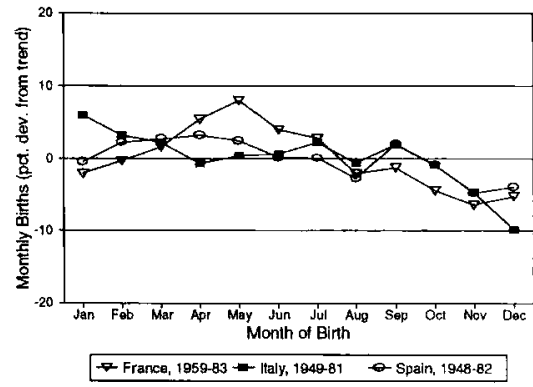

FIGURE 4. Seasonal birth patterns for Sweden, Finland, England, Netherlands, West Germany, Luxembourg, France, Italy, and Spain.

percent peak-to-trough difference in the most recent period. Births peak in April, in sharp contrast to the southern United States. A pronounced local peak also occurs in September. Most surprising is the increase in the amplitude of the seasonal pattern over time. The peak-to-trough difference increased from 17 percent in the 1921-38 
period to over 30 percent in the $1969-87$ period. Sweden has detailed vital statistics that make it possible to analyze birth seasonality separately for rural and urban areas. As reported in Lam and Miron ${ }^{5}$ the seasonal patterns for rural and urban areas are almost identical. Seasonality in rural areas was slightly higher than in urban areas earlier in this century, with a peak-to-trough amplitude of 18 percent compared to 14 percent in urban areas. Seasonality increased in both areas, rising to around 25 percent in both areas by the period 1948-64.

The seasonal pattern in Finland is quite similar to the Swedish pattern, with a March-April global peak and a September local peak. The overall magnitude is lower than Sweden's, with a peak-to-trough difference of about 20 percent. There is some evidence of an increase in seasonality in Finland, although we do not have reliable data from early in the century to make a complete comparison with the increases observed in Sweden.

The seasonal pattern for England is almost identical to the pattern for Canada observed in Figure 3. The reconstruction of parish birth series by Wrigley and Schofield ${ }^{12}$ make it possible to construct a 300 -year series of monthly births for pre-industrial England. As documented by Wrigley and Schofield and by Lam and Miron,${ }^{5}$ these parish reconstruction data show a dramatic decline in the amplitude of birth seasonality in England over time. The magnitude of seasonal fluctuations since 1948 is shown in FIgURE 4. Although the fluctuations are much smaller than in the pre-industrial period, a persistent seasonal pattern continues. The peak occurs in March, with a secondary local peak in September. The English pattern is similar to the patterns for Netherlands and West Germany, also shown in Figure 4. Both have seasonal amplitudes of slightly below 15 percent. Both show the typical European pattern of a March or April global peak, a local September peak, and an October through December trough.

The final two panels of FIGURE 4 show patterns for the central and southern European countries of Luxembourg, France, Italy, and Spain. These countries exhibit less dramatic seasonality than the northern European countries. A number of features of the "European pattern" persist, however, including the local September peak, and the October-December trough.

FigURE 5 shows seasonal patterns for a number of populations outside of North America and Europe. The patterns for three regions of India, Delhi, Maharashtra, and Punjab, are strikingly similar to patterns for southern regions of the United States. Delhi, the region of India with the most extreme amplitude in seasonality, has an April-May trough and a September peak, with a peak-to-trough amplitude of 60 percent, one of the highest we observe in any contemporary population. The second panel in Figure 5 shows the seasonal birth pattern for Israel for the period 1964-86. Israel's pattern is remarkably similar to that in the southern United States, exhibiting an April-May trough and September peak, with an amplitude of a little over 10 percent.

The third and fourth panels of Figure 5 show seasonal patterns for two Asian populations with reliable vital statistics data, Taiwan and Japan. The pattern for Taiwan displays a global November peak, a global May trough, and a local February peak. Seasonal birth fluctuations in Japan show a sharp January peak. As discussed in Lam and Miron, ${ }^{5}$ this may be due to a systematic reporting bias. Japanese births have a trough in May and June, and a local peak in September.

\section{Seasonal Patterns in the Southern Hemisphere}

It is natural to look to the southern hemisphere as a test for a number of hypotheses about birth seasonality, especially those based on seasonal variations in temperature or 
light. In practice, however, the evidence is inconclusive. The bottom panel of FIGURE 5 shows the seasonal birth patterns for the southern hemisphere countries of Australia, New Zealand, and South Africa.

The seasonal patterns for South Africa are shown separately for blacks and whites, as reported in published vital statistics. South African blacks in the period 1950-84

India - Delhi, Maharashtra, Punjab

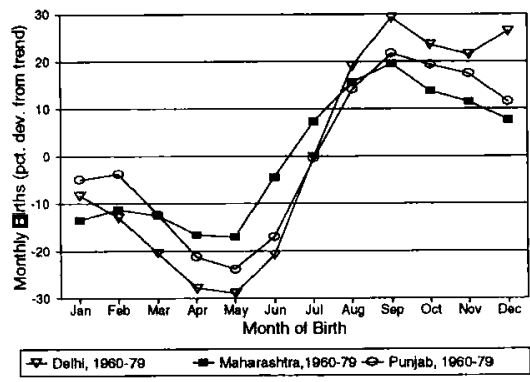

Taiwan

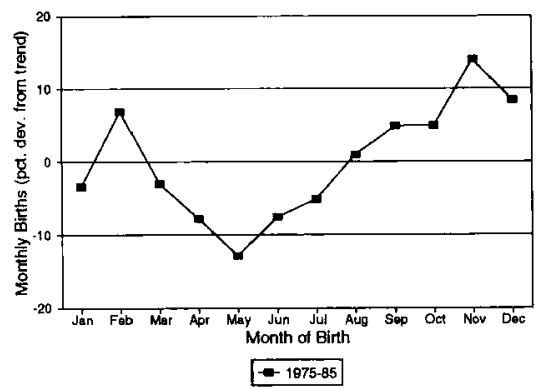

South Africa

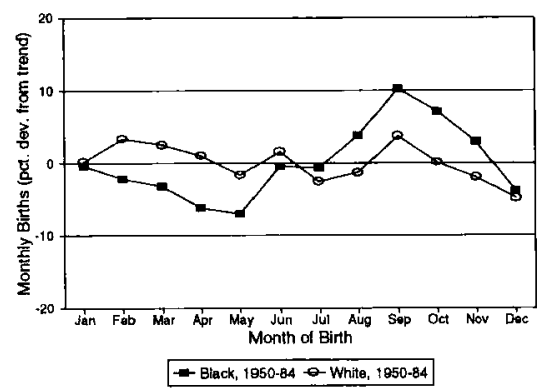

|srael

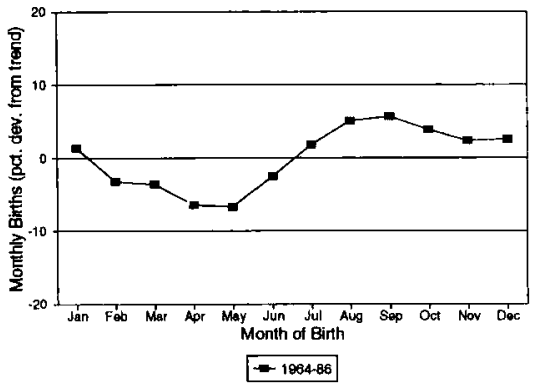

Japan - Kagoshima, Tokyo
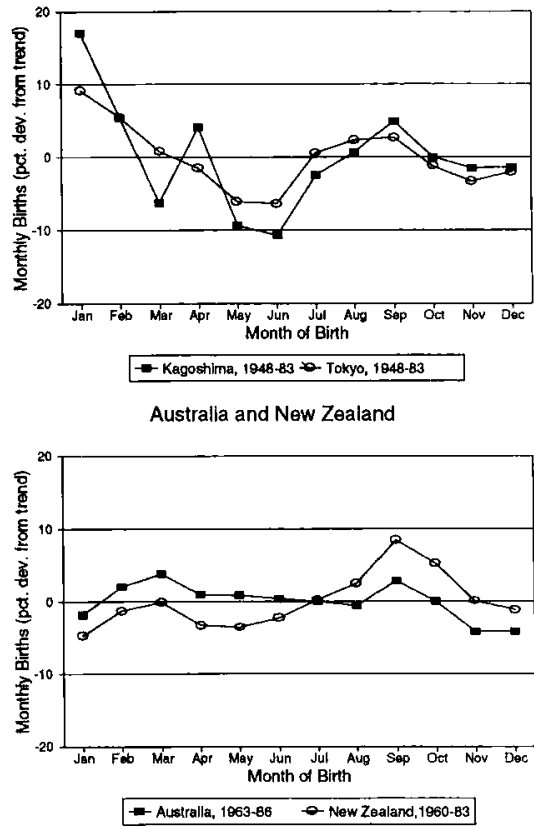

FIGURE 5. Seasonal birth patterns for India, Israel, Taiwan, Japan, South Africa, Australia, and New Zealand.

exhibit a pattern with a May trough and a September peak. This is strikingly similar to the pattern for the southern United States, a surprising result since the seasons are displaced by 6 months. Viewed from a different perspective, however, the SeptemberOctober peak in births among South African blacks is the mirror image of the 
March-April peak in births observed in many European populations. The pattern for South African whites is smaller in amplitude and somewhat different in shape, although whites display a September local peak and December trough similar to the pattern for blacks.

The Australian pattern in FIGURE 5 is characterized by a global March peak, a local September peak, and November-December trough. The existence of both September and March peaks makes it difficult to draw simple conclusions about comparisons across hemispheres. On the one hand, the pattern is surprisingly similar to the pattern for England in Figure 4, without making any 6-month displacement. On the other hand, it would also be fairly similar to the English pattern if displaced 6 months, since it would continue to be characterized by peaks in March and September. Studies of Australian seasonal patterns from earlier periods identify a September global peak. ${ }^{1-2}$ Rosenberg, ${ }^{2}$ for example, presents a seasonal pattern for South Australia for the period 1957-59 that is remarkably similar to the U.S. pattern in both timing and magnitude. Mathers and Harris ${ }^{13}$ analyze 3-year periods from 1962 to 1979 and conclude that the Australian pattern has shifted from a September peak in births to a March peak in births. ${ }^{14-17}$ The change in pattern they discuss is primarily a change in relative magnitudes. The March and September local peaks shown in our estimates in FIGURE 5 appear in virtually all periods in Australia, with the September peak being more predominant in earlier periods.

The pattern for New Zealand, also shown in FIGURE 5, demonstrates a seasonal pattern similar to that of Australia, but with the September peak significantly more pronounced. The New Zealand pattern, with the sharp September peak and AprilMay trough, displays several important features of the U.S. pattern. It is also quite consistent with a 6-month displacement of the English pattern, however. The surprisingly inconclusive nature of these cross-hemisphere comparisons is demonstrated graphically in FIGURE 6. The top panel plots the New Zealand pattern along with the pattern for Georgia. The patterns are remarkably similar, with an April-May trough and a September peak. The bottom panel shifts the New Zealand pattern by 6 months (plotting July births in January, etc.) and graphs this displaced pattern along with the English pattern. These two patterns are also quite similar, with a global March peak and a smaller local September peak. This is the consistency we would expect if the seasonal patterns were simply displaced by 6 months in the southern hemisphere, as would be implied by explanations based on temperature or photoperiod. The predominance of March and September peaks in a wide variety of populations in both hemispheres is an intriguing puzzle that makes it difficult to draw conclusions from comparing seasonal patterns of populations in different hemispheres.

\section{ENVIRONMENTAL DETERMINANTS OF BIRTH SEASONALITY}

Seasonal fluctuations in environmental factors are an obvious place to look for explanation of birth seasonality. The most popular explanations advanced in previous literature are based on temperature and photoperiod. In the remainder of this paper we will consider direct and indirect evidence on the role of temperature and photoperiod in explaining the major regional patterns in birth seasonality and in reconciling differences in patterns between regions. In addition to effects of temperature and photoperiod, seasonal patterns in marriages, holidays, temporary migration, and a variety of economic variables, including agricultural cycles, have been discussed as potential determinants of birth seasonality. For a discussion and evaluation of these factors, see Lam and Miron, ${ }^{5}$ and Becker. ${ }^{6}$ We do not consider these determinants here, but they may be working simultaneously to generate observed seasonal patterns. 
Georgia and New Zealand

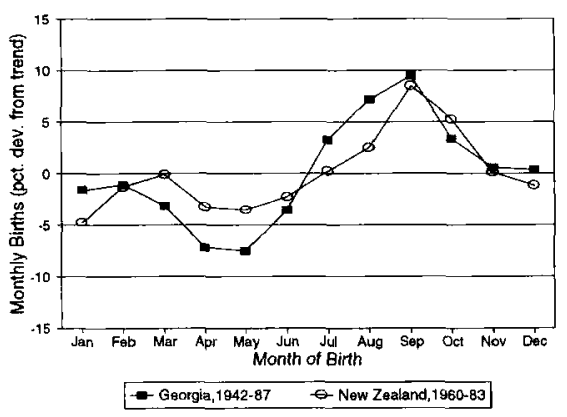

England and New Zealand (6 month lag)

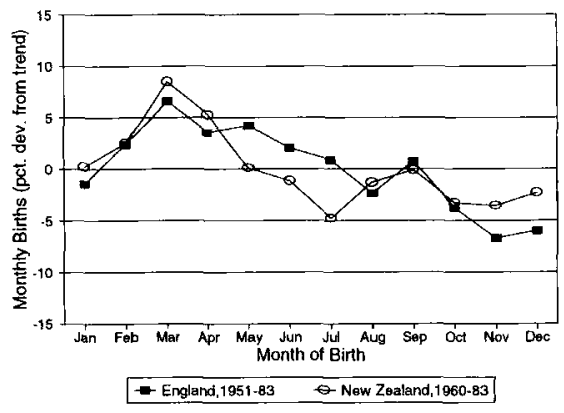

FIGURE 6. Seasonal birth patterns for Georgia and New Zealand, and patterns for England and New Zealand with 6-month lag.

Researchers have identified negative effects of short-term increases in temperature on births 9 months later in pre-industrial England ${ }^{18}$ and France, ${ }^{19}$ the southern United States, ${ }^{10}$ and rural Bangladesh. ${ }^{20-22}$ These apparent effects of temperature on conceptions may result from changes in coital frequency or may reflect direct physiological effects. Potential effects of ambient temperature on male reproductive capacity have been suggested by studies that show negative effects of heat on sperm count and sperm motility. ${ }^{23-25}$ Reviewing the evidence from nine studies, Levine ${ }^{26}$ finds a lowest values occurring in July through September and the highest values in February and March. The lowest and highest values averaged over all studies were 89 and 108 percent of the mean value. There is less direct evidence that temperature affects fecundability through physiological effects on females. Sundararaj et al. ${ }^{27}$ demonstrate that cycle lengths are shorter in summer months. The estimated effects imply small effects on fecundability, however, and imply increases in conceptions during summer months, contrary to observed patterns.

Research on non-human populations suggests that several factors, especially photoperiod, cause conceptions to be timed so that births are concentrated in the spring, when survival probabilities are highest. ${ }^{28}$ Although the relationship between photoperiod and seasonal breeding in animals is well established, little research analyzes effects of photoperiod on human reproduction. Ehrenkranz ${ }^{29,30}$ argues that photoperiod variations may explain seasonal variation in conceptions among Eskimo populations, but his results are based on small samples and provide only indirect evidence of a photoperiod effect. 


\section{Evidence from Non-seasonal Variation in Temperatures}

An instructive way to look at the effect of temperature on conceptions is to look at the relationship between non-seasonal variations in temperature and the number of conceptions in a given month. FIGURES 7,8 , and 9 show the results of such an analysis for a variety of states and countries. Temperature data for the United States (arithmetic averages over all the reporting weather stations in that state) are from Statewide Average Climatic History, ${ }^{31}$ and temperature data for other countries are from Monthly Climatic Data for the World. ${ }^{32}$ Conceptions are measured by assuming that births reported in a month correspond to conceptions 9 months earlier, an assumption that will never be cntirely accurate but that should not do great injustice to the data. As a measure of detrended monthly conceptions we continue to use the deviations from centered 12-month moving averages. We estimate the mean deviation from the 12-month trend for each month and then express each year's deviation relative to that mean.

FIGURE 7 shows the relationship between detrended monthly conceptions and monthly temperatures for the month of August in Georgia, during the period 1941-67, corresponding to births from January 1942 to December 1967. As the figure shows, there is substantial variation in mean August temperatures in Georgia, with a range of about $76^{\circ} \mathrm{F}$ to $83^{\circ} \mathrm{F}$ in the periods shown. The points in the scatter diagram imply, for example, that the coolest August in the period, with a mean temperature of about $76.5^{\circ} \mathrm{F}$, had about 7 percent more conceptions relative to the surrounding 12-month period than did a typical August. The figure shows a clear negative relationship between August temperature and August conceptions during the

FIGURE 7. Plot of detrended monthly conceptions (deviations from 12-month moving average) against mean monthly temperature, Georgia, $1941-67$ and $1968-87$.
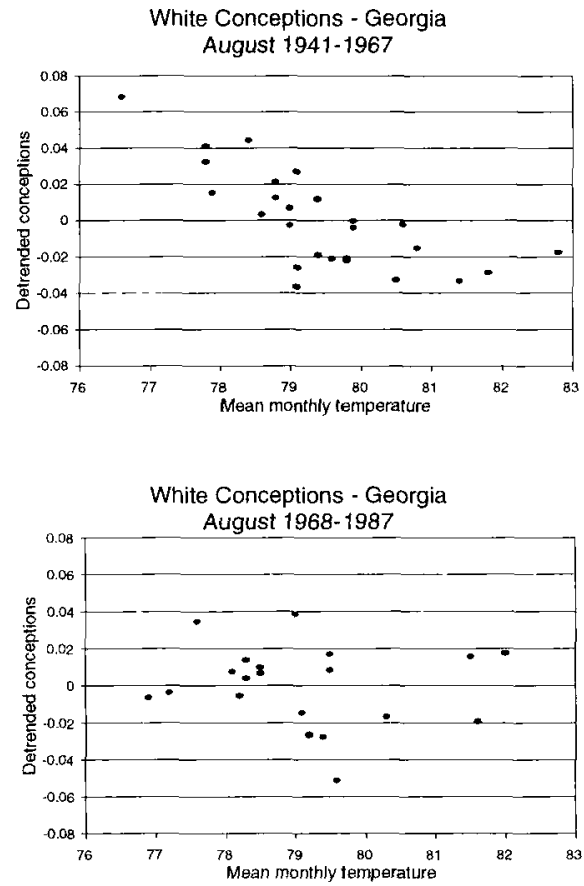
period $1941-68$. Beginning at $77^{\circ} \mathrm{F}$ this effect is such that a $5^{\circ} \mathrm{F}$ increase in temperature is associated with about a 10 percent decline in conceptions (i.e., about 6 percent above average to about 4 percent below average). This is a large effect and supports the view that hot temperatures play a role in explaining the April-May trough in births in the southern United States.

The bottom panel of the figure shows comparable data for the period 1968-88. The negative effect of August temperature has virtually disappeared in this later period. Although the range of temperatures is similar, there is essentially no relationship between temperature and conceptions. This is consistent with the result shown above that the magnitude of seasonality in white births in the southern states fell substantially between the earlier and later periods.

FIGURE 8 shows similar plots for 2 winter months in Georgia and for 4 months in New York for the period 1942-88. There is no significant relationship between temperature and conceptions during the months of December and January in Georgia. This is especially noteworthy because of the September peak in births in Georgia, a peak that appears to have no obvious direct link to December temperatures. Like Georgia, New York shows a clear negative relationship between temperature and conceptions in the summer months of July and August, but no relationship in the winter months of December and January.

Plots of conceptions against monthly temperature in Sweden are shown in FIGURE 9. Even though we observe a reasonable amount of variation in temperature in each month shown, we see little evidence that it affects conceptions. Looking at the plots for each month, there is little evidence that even changes in mean monthly temperature as large as $10^{\circ} \mathrm{F}$ lead to significant changes in monthly conceptions. It is especially important to note that there is little relationship between temperature and conceptions in June and July, which correspond to Sweden's peak in births in March and April. There is also no relationship between temperature and conceptions in March, which corresponds to Sweden's December trough in births. In general, we find little evidence that temperature plays a role in explaining Sweden's pronounced seasonal birth pattern.

In summary, looking at the relationship between temperature and conceptions in a single month over time provides mixed evidence on the role of temperature in explaining birth seasonality. In the United States we find strong evidence that extreme summer heat is important in explaining the trough in births in April and May and that this effect has declined over time. We see no evidence that temperature can explain the other features of the seasonal birth pattern in the United States such as the September peak. In Sweden, where the magnitude of seasonal fluctuations is the same order of magnitude as the southern United States, we find virtually no evidence that temperature fluctuations are an important cause of the seasonality.

\section{Controlling for Effects of Temperature}

Another exercise that can be done to analyze the role of temperature on birth seasonality is to include temperature variables in regressions that also include monthly dummies. This is the approach taken in Lam and Miron. ${ }^{33}$ Using this estimation strategy means we identify the effects of temperature entirely from the non-seasonal variance in temperature. If the temperature in each month were identical every year (i.e., there were no non-seasonal variation in temperature), our monthly temperature variable would be an exact linear combination of the monthly dummies. We would have a singular cross-product matrix and would be unable to estimate the regression. We require enough non-seasonal variation in temperature to identify an effect that is 
independent of the monthly dummies. Although the seasonal variation in temperature is far greater than non-seasonal variation (the $R^{2}$ of monthly temperature on monthly dummies in our populations is typically over .9), we have enough non-seasonal variation to identify the effect of temperature. As demonstrated in the previous figures
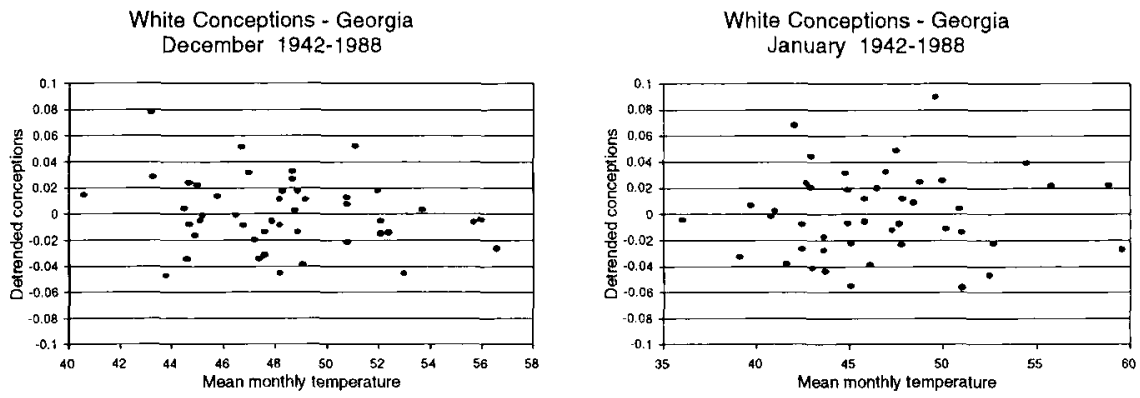

White Conceptions - New York July 1942-1988

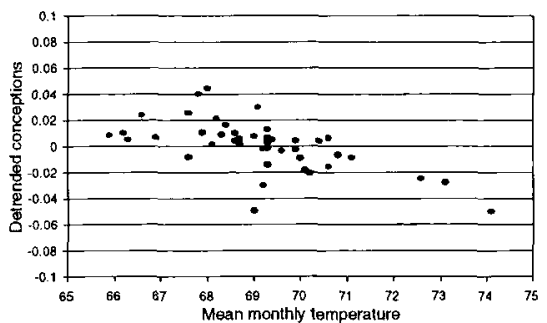

White Conceptions - New York August $1942-1988$

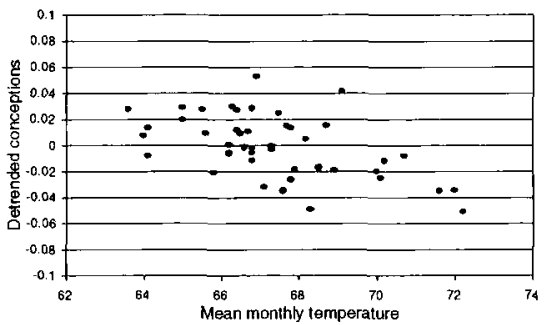

White Conceptions - New York December 1942-1988

White Conceptions - New York January 1942-1988
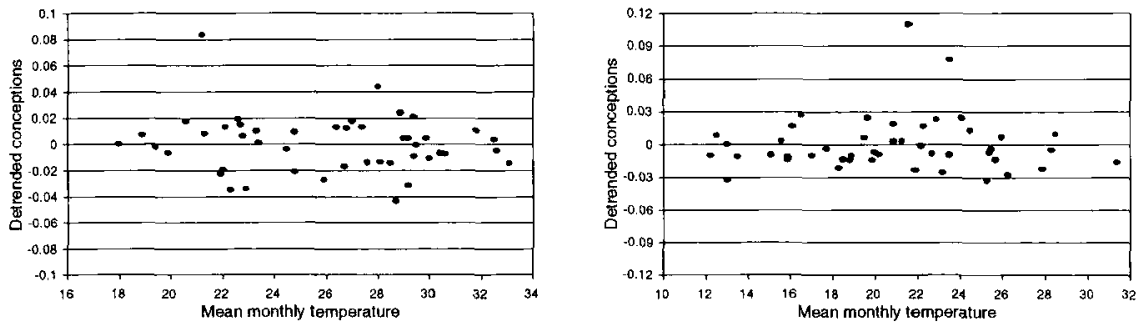

FIGURE 8. Plot of detrended monthly conceptions (deviations from 12-month moving average) against mean monthly temperature, Georgia and New York, 1942-88.

for Georgia, New York, and Sweden, we observe variations in mean monthly temperatures over a range of around $10^{\circ} \mathrm{F}$ over our sample periods.

Assuming that seasonal variations in temperature have the same effect as nonseasonal variations in temperature (i.e., that $100^{\circ} \mathrm{F}$ weather has the same effect on 
Sweden - March

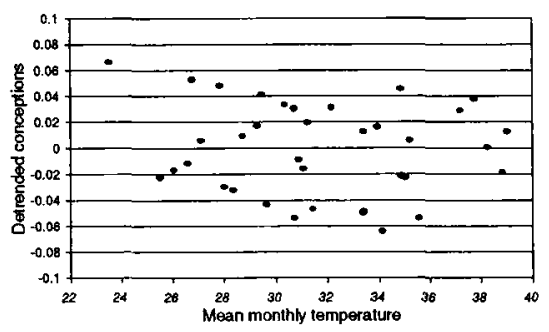

Sweden - June

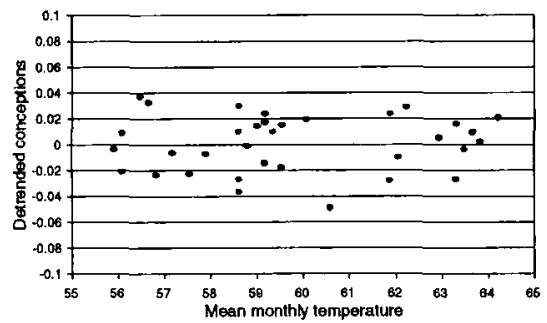

Sweden - December

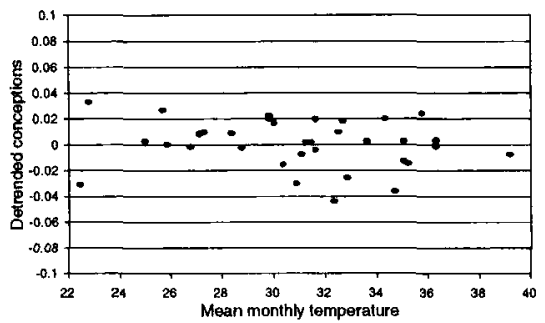

Sweden - May

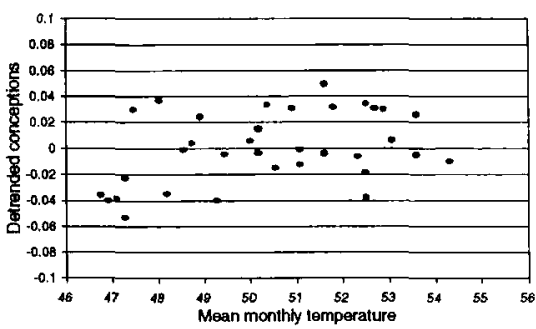

Sweden - July

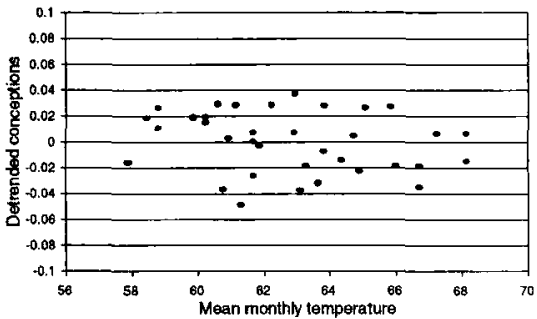

Sweden - January

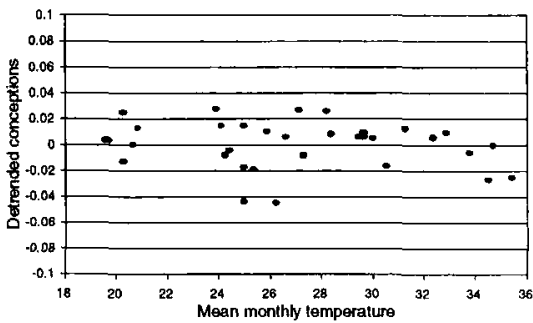

FIGURE 9. Plot of detrended monthly conceptions (deviations from 12-month moving average) against mean monthly temperature, Sweden, 1949-85.

conceptions whether it occurs predictably in August or unpredictably in May), then our regressions provide a test of the extent to which seasonal variations in births are entirely due to weather. Assuming we have allowed a sufficiently flexible functional form, inclusion of weather variables should drive the monthly dummy coefficients to zero if seasonality is entirely caused by weather. Similarly, any effects of monthly dummies remaining after controlling for weather indicate effects that are not related to weather or due to systematic differences in the effects of seasonal vs. non-seasonal variation in the weather.

We have applied this estimation strategy to a number of states and countries. The specification uses the log of detrended monthly births as the dependent variable and includes lags 9 and 10 of temperature and temperature squared and monthly dummies 
as independent variables. FIGURES 10 and 11 present the estimated seasonal patterns for a variety of populations before and after including monthly temperature in the regression. The solid line in each graph is the seasonal pattern we estimate when we do not include temperature variables. The dotted line is the seasonal pattern we estimate when we include temperature variables.

FIGURE 10 shows the results for several states in the United States estimated over the period 1942-88. The first panel shows the results for white births in Georgia. As we would predict, controlling for temperature 9 and 10 months before the birth reduces the magnitude of the trough in births in April and May, corresponding to conceptions in July and August. The magnitude of the peak-to-trough amplitude is
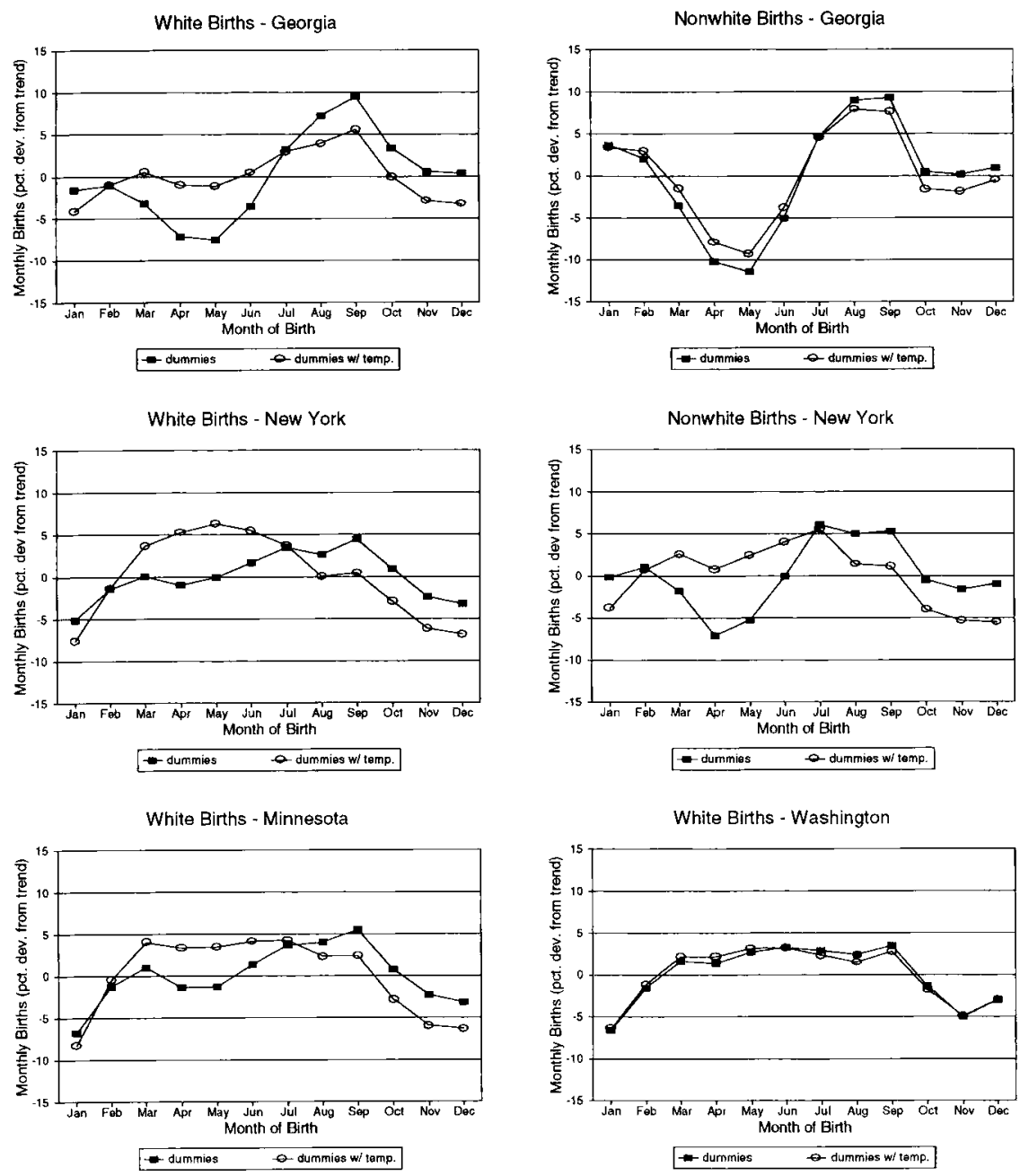

FIGURE 10. Seasonal birth patterns with and without controls for monthly temperature, United States, 1942-88. 
roughly cut in half when lagged temperature is included in the regression. The second panel shows that controlling for temperature has a much smaller effect on the seasonal pattern for nonwhite births. This is a puzzle, since the greater degree of seasonality for nonwhites is often attributed to more limited access to air conditioning, suggesting that nonwhite births would be more affected by variations in temperature. This should imply that removing the effects of temperature would cause a bigger reduction in the estimated seasonal pattern.

Looking at the results for the northern states of New York and Minnesota, we see that the pattern before controlling for the weather is roughly a dampened version of the pattern for the southern United States, with a small April-May trough and a September peak in births. The pattern after controlling for the weather is substantially different than the pattern observed in the South, however. Controlling for lagged temperature tends to eliminate the April-May trough in births and in most cases introduces a peak in births in spring and/or early summer. Controlling for temperature has little effect in Washington, although there is a small increase in births in March, April, and May.

FIGURE 11 shows the same estimation exercise for six other countries, Sweden, England, France, Canada, Australia, and New Zealand. Temperatures are for the cities of Stockholm, London, Paris, Toronto, Sydney, and Christchurch. The first four are characterized by a European pattern of birth seasonality, with a global peak in births in the spring and a local peak in September. None exhibit the April-May trough typical of the U.S. pattern. As the graphs in FIGURE 11 indicate, controlling for monthly temperature in these countries never has the effect of reducing the magnitude of the seasonal pattern. In Sweden and England there is virtually no change in the seasonal pattern after controlling for lagged temperature. In France and Canada there is an increase in the magnitude of the April-May peak after controlling for temperature. Recall that a similar result was observed for New York and Minnesota in FIGURE 10. This apparent increase in seasonality when weather effects are removed is surprising but consistent with removing a depressing effect of summer heat on conceptions. The effect of summer heat may be too small in these temperate northern populations to cause an observed trough in spring conceptions but may nonetheless dampen what would otherwise be an even more pronounced tendency for spring births.

In the southern hemisphere countries of Australia and New Zealand we find little effect of controlling for temperature. It is intriguing to note, however, that there is a small increase in the spring peak in births after controlling for lagged temperature. The results imply that births would be even higher in September in both Australia and New Zealand if there were constant temperature throughout the year.

In general these results indicate that controlling for temperature effects helps reconcile the differences in seasonal patterns across populations. In almost every population considered, the inclusion of temperature leads to an increase in the relative number of spring births. Populations with large spring troughs, such as the southern United States, have smaller troughs after inclusion of the weather. Populations with modest spring troughs, such as the northeastern United States, change from spring troughs to spring peaks. Populations with spring peaks display greater peaks when monthly temperature is included in the regression.

\section{CONCLUSION}

Comparison of seasonal patterns in births across populations demonstrates that the most pronounced patterns are found in regions with extreme summer heat and in regions at extreme latitudes. Regions with extreme summer heat, such as the southern 
United States, have substantial reductions in conceptions during the hottest months. We show that this effect was as large as a 45 percent difference between peak and trough births in Louisiana during the period 1942-68. This effect has declined substantially over time. Countries of northern Europe are characterized by a large

Sweden, 1949-84

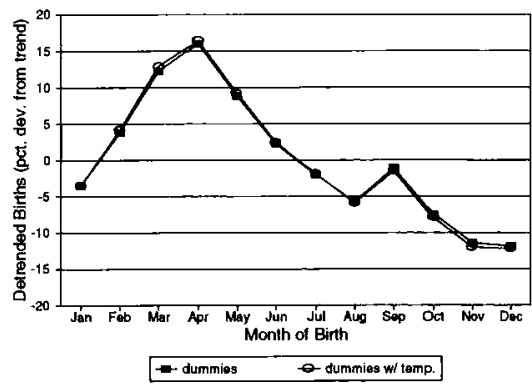

France, 1959-83

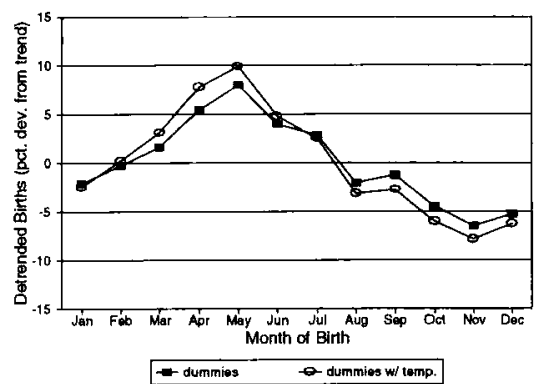

Australia (S), 1963-84

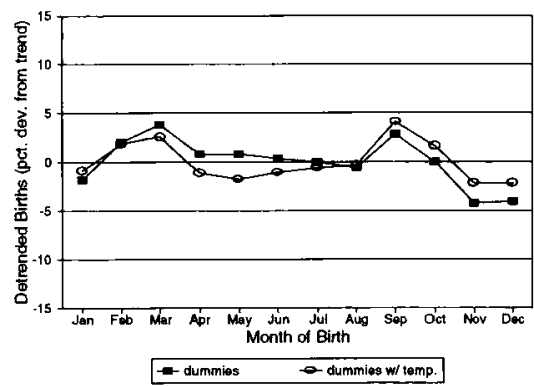

England, 1951-83

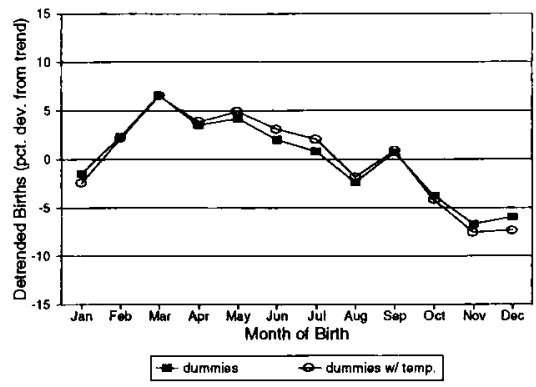

Canada (T), 1949-76

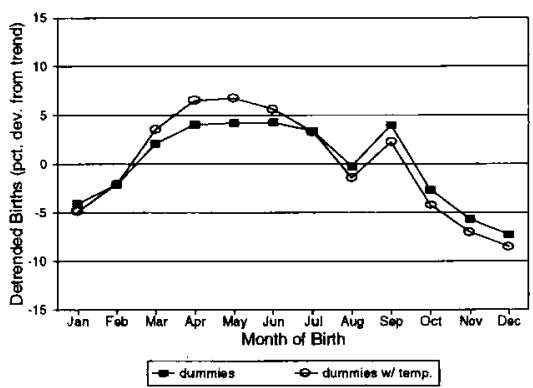

New Zealand (C), 1960-83

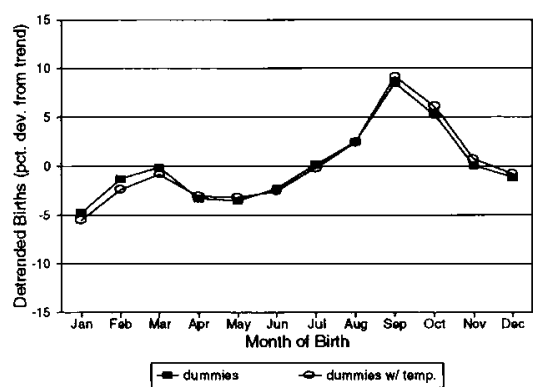

FIGURE 11. Seasonal birth patterns with and without controls for monthly temperature, selected countries.

spring peak in births. In Sweden this seasonal peak has actually increased during the twentieth century, reaching a peak-to-trough magnitude of almost 30 percent. Comparisons of patterns across hemispheres is surprisingly inconclusive. This results from the fact that countries with reliable vital statistics data in both hemispheres tend to be 
characterized by global or local peaks in births in both March and September. As a result the patterns in New Zealand and Australia can be interpreted as consistent with either a 6-month displaced version of the European pattern or with an undisplaced version of the U.S. pattern.

Our results provide mixed evidence regarding the effects of monthly temperature. Looking at seasonal birth patterns, we observe a tendency for a spring trough in births in a number of warm climate populations, suggesting that hot summers reduce conceptions. We also observe a number of patterns without obvious temperature explanations, including a persistent September local peak in births and a spring peak in births in northern populations. Using data on monthly temperatures across years, we find that above-average temperatures in July and August are associated with belownormal conceptions in both southern and northern states in the United States. This negative relationship has declined over time, however, consistent with the decline in magnitude of seasonal fluctuations. We find virtually no relationship, however, between temperature and conceptions in the winter months in the United States. We also find no evidence that non-seasonal variations in temperature affect the number of conceptions in either the summer or winter months in Sweden. This suggests that temperature is not a major determinant of Sweden's pronounced seasonal pattern.

Looking at the seasonal pattern in births when we statistically control for the effects of monthly temperature, we find that we can substantially reduce the April-May trough in births in the southern United States. In northern states we often eliminate that trough completely and introduce a March peak, similar to the European pattern. Controlling for temperatures has almost no effect on the estimated seasonal birth pattern in Europe and sometimes increases the magnitude of this peak. These results suggest that two different forces may be driving the seasonal patterns in the southern United States and northern Europe. The southern U.S. pattern appears to be heavily influenced by summer heat, but the northern European pattern appears to have little to do with temperature. Although we have no direct evidence that photoperiod is responsible for the European pattern, our results are consistent with that explanation.

\section{SUMMARY}

Pronounced and persistent seasonal patterns in fertility are observed in virtually all human populations. This paper presents evidence on these seasonal patterns. We note that the most pronounced seasonal patterns are in the southern United States, where births decline substantially in April and May, and in northern Europe, where births increase substantially in March and April. Although seasonal variations in fertility were more pronounced in earlier agricultural populations, we show that seasonality has increased in this century in some high income, low fertility populations such as Sweden. We use data on monthly temperature to analyze the potential role of temperature in explaining seasonal patterns. We find strong evidence that summer heat plays an important role in explaining the July-August trough in conceptions in the southern United States. We find little evidence, however, that temperature plays any role in explaining the pronounced June-July peak in conceptions in Sweden. Temperature also appears to be relatively unimportant in several other populations with substantial seasonal variations in births, suggesting that other factors play an important role in birth seasonality. 


\section{ACKNOWLEDGMENTS}

This paper has benefited from discussions with Stan Becker, Dan Seiver, and Joe Rodgers. Excellent research assistance was provided by Todd Clark, Ranya Dajani, and Laura Phillips.

\section{REFERENCES}

1. Cowgill, U. M. 1965. Season of birth in man, contemporary situation with special reference to Europe and the Southern Hemisphere. Ecology 47(4): 614-623.

2. ROSENBERG, H. M. 1966. Seasonal variation of births. Washington, D.C.: National Center for Health Statistics 21: 9.

3. Kevan, S. M. 1979. Season of life-Season of death. Social Science Medicine 13D: $227-$ 232.

4. Dyson, T. \& N. Crook. 1981. Causes of seasonal fluctuations in vital events. In Seasonal Dimensions to Rural Poverty. R. Chambers et al., Eds.: 135-162. London: Frances Pinter.

5. LAM, D. \& J. Miron. 1991a. Seasonality of births in human populations. Social Biology 38(1-2): 51-78.

6. BECKER, S. 1991. Seasonal patterns of births and conception throughout the world. In Temperature and Environmental Effects on the Testis. A. W. Zorgniotti, Ed.: 59-72. New York: Plenum.

7. MACFARI.ANE, W. V. 1970. Seasonality of conception of human populations. Biometeorology 4(1): 167-182.

8. LYSTER, W. R. 1971. Three patterns of seasonality in American births. American Journal of Obstetrics and Gynecology 1 10: 1025-1028.

9. SeIver, D. 1985. Trend and variation in the seasonality of U.S. fertility, 1947 to 1976. Demography 22: 1, February.

10. Seiver, D. 1989. Seasonality of fertility: New evidence. Population and Environment 10(4): 245-257.

11. Querec, L. J. \& E. Spratley. 1978. Characteristics of births, United States, 1973-1975. Vital and Health Statistics Series 21, Number 30. Washington, D.C.: National Center for Health Statistics.

12. Wrigley, E. A. \& R. SChorield. 1981. The Population History of England, 1541-1871: A Reconstitution. Cambridge, MA: Harvard University Press.

13. MATHERS, C. D. \& R. S. HARris. 1983. Seasonal distribution of births in Australia. International Journal of Epidemiology 12(3): 326-331.

14. MacFarlane, W. V. \& D. Spalding. 1960. Seasonal conception rates in Australia. The Medical Journal of Australia: 1: 121-124.

15. Lyster, W. R. 1979. New seasonal distribution of births in New South Wales. The Medical Journal of Australia 2: 150.

16. Parker, G. 1978. Season of birth in New South Wales. The Medical Journal of Australia 2: 563-566.

17. Parker, G. 1979. New seasonal distribution of births in New South Wales. The Medical Journal of Australia 2: 424.

18. LEE, R. D. 1981. Short-term variation: Vital rates, prices and weather. In The Population History of England, 1541-1871: A Reconstitution. E. A. Wrigley \& R. Schofield, Eds.: 356-401. Cambridge, MA: Harvard University Press.

19. Richards, T. 1983. Weather, nutrition, and the economy: Short-run fluctuations in births, deaths, and marriages, France 1740-1909. Demography 20: 197-212.

20. BeCker, S., A. Chowdhury \& H. Leridon. 1986. Seasonal patterns of reproduction in Matlab, Bangladesh. Population Studies 40: 457-472.

21. Stoeckel, J. \& A. K. M. A. ChowdhuRy. 1972. Seasonal variation in births in rural East Pakistan. Journal of Biosocial Science 4: 107-116. 
22. BECKER, S. 1981. Seasonality of fertility in Matlab, Bangladesh. Journal of Biological Science 13: 97-105.

23. SPIRA, A. 1991. Epidemiologic aspects of the relationship between temperature and the male reproduction. In Temperature and Environmental Effects on the Testis. A. W. Zorgniotti, Ed.: 49-56. New York: Plenum.

24. LAVEN, J. S. E., M. J. HAVERKORN \& R. BOTS. 1988. Influence of occupation and living habits on semen quality in men. European Journal of Obstetrics Gynecology and Reproductive Biology 29: 137-141.

25. LANMAN, J. T. 1968. Delays during reproduction and their effects on the embryo and fetus. New England Journal of Medicine 278(18): 993-999 and 278(19): 1047-1054.

26. LEVINE, R. J. 1991. Seasonal variation in human semen quality. In Temperature and Environmental Effects on the Testis. A. W. Zorgniotti, Ed.: 89-66. New York: Plenum.

27. Sundarara, N., M. Chern, L. Gatewood, L. Hickman \& R. MCHugh. 1978. Seasonal behavior of human menstrual cycles: A biometric investigation. Human Biology 50(1): $15-31$.

28. Karsch, F. J., E. L. Bittman, D. L. Foster, R. L. Goodman, S. J. Legan \& J. E. ROBINSON. 1984. Neuroendocrine basis of seasonal reproduction. Recent Progress in Hormone Research 40: 185-232.

29. Ehrenkranz, J. R. L. 1983a. A gland for all seasons. Natural History 6: 18-23.

30. EhreNkranZ, J. R. L. 1983b. Seasonal breeding in humans: Birth records of the Labrador Eskimo. Fertility and Sterility 40(4): 485-489.

31. National OCEanic and Atmospheric Administration. 1988. State, regional, and national monthly and annual temperature: Weighted by area for the contiguous United States, January 1931-December 1987. Historical Climatology Series 4-1. Asheville, N.C.: National Climatic Data Center.

32. National Oceanic and Atmospheric Administration. Various Dates. Monthly climatic data for the world: prepared in cooperation with the world meteorological organization. Various volumes. Asheville, N.C.: National Climatic Data Center.

33. LAM, D. \& J. MIRON. 1991b. Temperature and the seasonality of births. In Temperature and Environmental Effects on the Testis. A. W. Zorgniotti, Ed.: 73-88. New York: Plenum. 